\title{
Praktik Ekowisata Di Kampung Waerebo Kabupaten Manggarai, Provinsi Nusa Tenggara Timur
}

\author{
Maria Ariyanti Pandung a,1, I Nyoman Sukma Arida a,2 \\ 1anpandung@gmail.com, 22sukma_arida@unud.ac.id \\ a Program Studi S1 Destinasi Pariwisata, Fakultas Pariwisata,Universitas Udayana, Jl. Dr. R. Goris, Denpasar, Bali 80232 Indonesia
}

\section{Abstract}

The purpose of this research was to determine ecotourism practice in Wae Rebo Village and to determine involvement of stakeholder such as local community, government, and investor. This research was conducted in Wae Rebo village with a survey method. Data was collected through observation and indepth interviews to the informan. Speaker retrieval method is random with interviewing stackeholders such as adviser of LPBW (Lembaga Pelestarian Budaya Waerebo) all at once representation of young generation and owner of travel agent, representation of guide community, representation of souvenir seller community, representation of local community, representation of homestay owner, and representation of tourism departement as a section head of tourism destination development. The data were analyzed using the ecotourism concept according to Fennel (Arida, 2009) and World Conservation Union (WCU in Arida, 2009). These results indicate that ecotourism practices in Wae Rebo Village have happened agree with ecotourism concept and ecotourism principle. Local community have a big role in the management of that gets a lot of help from various travel agent in promoting Wae Rebo.

Keywords: ecotourism, organizer, local community

\section{PENDAHULUAN}

Ekowisata merupakan salah satu bentuk wisata khusus. Bentuknya yang khusus itu menjadikan ekowisata sering diposisikan sebagai antitesa dari pariwisata massal. Sebenarnya yang lebih membedakannya dari pariwisata massal adalah karakteristik produk dan pasar (Damanik dan Weber, 2006). Ekowisata merupakan kegiatan wisata yang menaruh perhatian besar terhadap kelestarian sumber daya pariwisata (Damanik dan Weber, 2006). Jika karateristik pariwisata massal lebih mengutamakan jumlah kunjungan wisatawan, maka ekowisata lebih mengutamakan kualitas wisatawan yang berkunjung (quality tourist).

$$
\text { Damanik dan Weber (2006) }
$$

mengungkapkan bahwa terdapat empat ciri utama yang dapat membedakan ekowisata dengan jenis wisata lainnya. Pertama, yaitu kegiatan ekowisata harus lebih banyak berkaitan dengan konservasi lingkungan. Kedua, Menawarkan peluang bagi wisatawan untuk ikut menghargai lingkungan maupun kebudayaan masyarakat lokal sehingga baik wisatawan maupun masyarakat lokal saling menikmati dan sekaligus melestarikan lingkungan dan kebudayaan tersebut. Ketiga, daya tarik atau atraksi wisata yang ditawarkan kepada wisatawan adalah berbasis alam atau budaya dengan tujuan wisatawan dapat menikmati keunikan atau keaslian budaya tersebut sehingga wisatawan dapat mencapai kepuasan tertinggi dalam berwisata. Keempat, partisipasi aktif masyarakat lokal sangat diperlukan dalam kegiatan ekowisata dengan tujuan masyarakat lokal dapat merasakan keuntungan secara langsung dari kegiatan ekowisata tersebut untuk peningkatan kesejahteraan hidup masyarakat lokal itu sendiri.

Ekowisata adalah salah satu jenis wisata yang banyak dikembangkan di Provinsi Nusa Tenggara Timur (NTT) saat ini . NTT merupakan salah satu provinsi di Indonesia yang mempunyai kekayaan sumber daya alam dan budaya yang beranekaragam serta memiliki keunikan tersendiri yang tidak dimiliki oleh kebudayaan lainnya. Oleh karena kekayaan sumber daya dan kebudayaan tersebut maka NTT mempunyai peluang yang sangat besar untuk dikembangkan sebagai destinasi berbasis ekowisata. Terdapat dua dari tujuh keajaiban dunia di Provinsi NTT yaitu pertama keberadaan hewan langka Komodo dan Danau Kelimutu yang dikenal dengan tiga kawah danau dengan masing-masing warna yang berbeda. Keberadaan kedua destinasi ini menempatkan NTT sebagai Provinsi yang sudah dikenal secara nasional maupun internasional. 
Manggarai merupakan salah satu kabupaten di NTT yang saat ini sedang mengembangkan ekowisata. Salah satu destinasi yang sedang gencar dikembangkan adalah Kampung Waerebo. Waerebo sendiri merupakan sebuah kampung adat dengan daya tarik yang unik yaitu mbaru niang sebagai satusatunya peninggalan rumah adat Masyarakat Mangggarai yang masih tertinggal sampai dengan saat ini. Kampung Waerebo lebih banyak dikunjungi oleh wisatawan mancanegara yang ingin menyaksikan dan merasakan kehidupan masyarakat lokal yang tinggal dalam mbaru niang tersebut dengan keunikan dan kebudayaannya yang masih asli serta jauh dari hiruk pikuk kehidupan yang modern. Kampung Waerebo mendapatkan penghargaan Award of Excellence pada tahun 2012 dari Organisasi Pendidikan, Ilmu Pengetahuan, dan Kebudayaan PBB atau UNESCO kawasan Asia Pasifik.

Kegiatan ekowisata sangat diminati oleh wisatawan yang berkunjung ke Kampung Waerebo karena selain keberadaan kampung ini yang jauh dari keramaian, wisatawan dapat merasakan kehidupan masyarakat lokal yang masih menyatu dengan alam dan sangat terikat dengan kebudayaannya yang unik. Wisatawan yang berkunjung mendapatkan pengalaman dan pengetahuan yang baru mengenai struktur arsitektur dan fungsi dari masing-masing mbaru niang. Selain itu wisatawan juga dapat mempelajari kesenian masyarakat lokal yaitu menenun dan mempelajari upacara adat atau ritual adat masyarakat Waerebo. Berdasarkan penjelasan di atas, penelitian ini bertujuan untuk mengetahui praktik ekowisata di Kampung Waerebo, Kabupaten Manggarai.

\section{TINJAUAN PUSTAKA}

\section{1 Konsep Ekowisata}

Ekowisata merupakan wisata berbasis alam yang berkelanjutan dengan fokus pengalaman dan pendidikan tentang alam, dikelola dengan sistem pengelolaan tertentu dan memberi dampak negatif paling rendah terhadap lingkungan, tidak bersifat konsumtif dan berorientasi pada lokal (dalam hal kontrol, manfaat yang dapat diambil dari kegiatan usaha, ( Fennel, dalam Arida ,2009).

Menurut World Conservation Union (WCU dalam Arida,2009), ekowisata adalah perjalanan bertanggung jawab secara ekologis, mengunjungi daerah yang masih asli (pristine) untuk menikmati dan menghargai keindahan alam (termasuk kebudayaan lokal) dan mempromosikan konservasi.

Berdasarkan konsep-konsep ekowisata di atas, maka konsep ekowisata menurut Fennel dan World Conservation Union akan menjadi acuan dalam mendeskripsikan tentang praktik ekowisata di Desa Wae Rebo sehingga yang dimaksud dengan ekowisata dalam penelitian ini adalah kegiatan mengunjungi suatu daya tarik wisata untuk menikmati alam maupun kebudayaan yang masih asli dengan mengutamakan kegiatan konservasi sehingga dapat terwujudnya kesejahteraan masyarakat lokal.

\section{METODE PENELITIAN}

Lokasi penelitian ini yaitu di Kampung Waerebo yang berada di Desa Satar Lenda, Kecamatan Satarmese Barat, Kabupaten Manggarai, Propinsi Nusa Tenggara Timur. Karena berada di ketinggian 1200 mdpl, maka hawa di Kampung ini cukup dingin. Kampung Wae Rebo berada diantara gunung dan hutan lebat serta jauh dari kampung-kampung tetangga. Untuk mencapai Kampung Waerebo wisatawawan melakukan trekking selama empat jam.

Teknik pengumpulan data yang akan digunakan dalam penelitian ini adalah observasi, wawancara mendalam, dan studi kepustakaan. Aspek data yang diperoleh mencakup penyelengaraan ekowisata di Kampung Waerebo. Selanjutnya data yang terkumpul dianalisis menggunakan teknik reduksi data, penyajian data, dan yang terakhir dilakukan penarikan kesimpulan, dijabarkan dalm bentuk deskriptif kualitatif.

Teknik penentuan informan yang akan digunakan adalah teknik purposive samping dengan memilih narasumber yang dianggap memiliki pengetahuan mendalam mengenai aspek data yang akan dicari, seperti ketua adat (tu'a mbaru gendang) Kampung Waerebo, Ketua Badan Pengelola DTW Kampung Waerebo, Kepala Dinas Pariwisata Kabupaten Manggarai, perwakilan travel agent, perwakilan masyarakat lokal yang mengelola akomodasi pariwisata (homestay) dan perwakilan generasi muda di Waerebo. 


\section{HASIL DAN PEMBAHASAN}

\subsection{Praktik Ekowisata di Kampung Waerebo (Atraksi)}

Keberadaan mbaru niang menjadikan Warebo sebagai sebuah kampung yang unik dan otentik. Keindahan alam dan keunikan budaya menjadi daya tarik utama bagi wisatawan. Kehidupan masyarakat lokal yang masih terikat dengan adat istiadat beserta benda-benda fisik peninggalan leluhur merupakan aset utama Kampung Waerebo. Daya tarik utama yang terdapat di Kampung Waerebo adalah mbaru niang (rumah adat) dan kehidupan masyarakat adat ( Dokumentasi dari buku "Pesan-pesan dari Waerebo"). Mbaru niang merupakan lambang perlindungan dan persatuan bagi masyarakat Waerebo yang berbentuk kerucut meruncing ke arah atas. Lantai bangunan mbaru niang yang berbentuk lingkaran dimaknai oleh masyarakat lokal sebagai simbol keharmonisan serta keadilan yang terjalin antar warga dan keluarga di dalam mbaru niang.

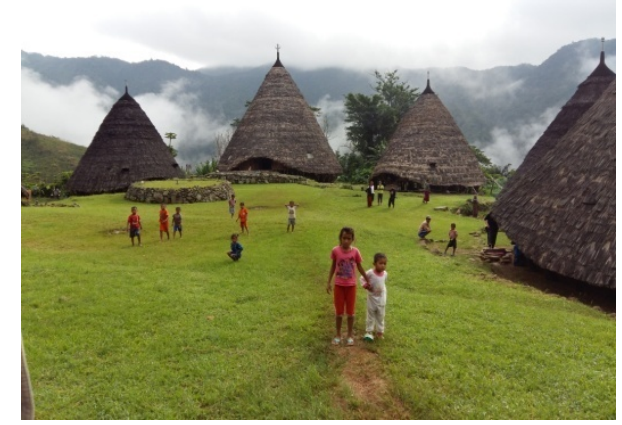

Gambar 4.1 Mbaru Niang

Sumber: Dokumentasi Pribadi, 2016

Di Kampung Waerebo terdapat tujuh bangunan mbaru niang yang dipercaya oleh masyarakat lokal sebagai bentuk penghormatan kepada tujuh arah puncak gunung yang mengelilingi Kampung Waerebo. Ketujuh puncak gunung tersebut diyakini oleh masyarakat sebagai "para pelindung" kemakmuran kampung. Ketujuh mbaru niang tersebut mengelilingi compang yaitu sebuah altar batu atau pelataran yang merupakan tempat untuk penyembahan kepada Tuhan maupun leluhur. Compang merupakan titik pusat dari keberadaan tujuh mbaru niang dan merupakan tempat yang diyakini paling sakral oleh masyarakat lokal. Ketujuh mbaru niang yang terdapat di Kampung Waerebo memiliki nama adat yang berbeda satu dengan yang lainnya meliputi: Niang Gendang, Niang Gena Mandok, Niang Gena Jekong (dibangun ulang pada tahun 2010), Niang Gena Ndorom (dibangun ulang pada tahun 2009), Niang Gena Keto, Niang Gena Jintam, Niang Gena Maro ( Dokumentasi dari buku "Pesan-pesan dari Waerebo").

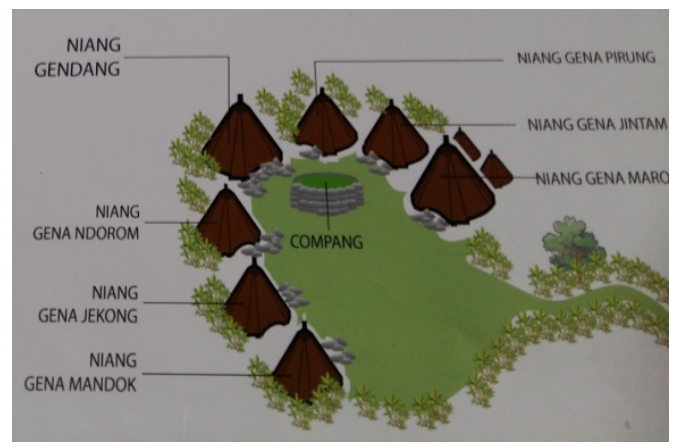

Gambar 4.2 Penamaan Mbaru Niang

Sumber: Dokumentasi Pribadi, 2016

Lantai pertama pada mbaru niang yang disebut dengan tenda merupakan ruang kegiatan bagi keluarga maupun masyarakat lokal. Diameter mbaru niang utama atau yang disebut dengan niang gendang miliki diameter sekitar 14 meter sedangkan keenam mbaru niang lainnya memiliki diameter sekitar 11 meter. Perbedaan tersebut yaitu berdasarkan jumlah keluarga yang menghuni masing-masing mbaru niang. Masing-masing mbaru niang terdiri dari lima tingkat dengan fungsi yang berbeda-beda yaitu sebagai berikut: (1). Tingkat pertama yang disebut Tenda. Tenda merupakan ruang bagi penghuninya untuk melakukan segala aktivitas. Pada tingkat pertama ini terdapat ruang untuk berkumpul bagi penghuni maupun masyarakat lainnya, ruang tungku atau disebut juga sebagai dapur dan ruang untuk makan serta kamar-kamar tidur bagi penghuni mbaru niang yang biasanya terdiri dari enam sampai delapan kepala keluarga. (2). Tingkat kedua yaitu Lobo. Pada tingkat kedua dalam mbaru niang ini digunakan oleh masyarakat sebagai tempat untuk menyimpan bahan makanan dan barangbarang yang lain. (3). Tingkat ketiga adalah Lentar yang difungsikan oleh masyarakat lokal sebagai tempat untuk menyimpan benih-benih tanaman ladang dan kebun. (4). Tingkat keempat yaitu Lempa Rae. Pada tingkat ini, masyarakat menggunakannya sebagai ruang 
atau tempat untuk menyimpan cadangan makanan. (5). Tingkat kelima sebagai tingkat yang paling tinggi adalah Hekang Kode merupakan tempat yang sakral karena berfungsi sebagai tempat untuk menyimpan sesajen kepada leluhur yang berupa anyaman bambu. (Dokumentasi dari buku "Pesan-pesan dari Waerebo").

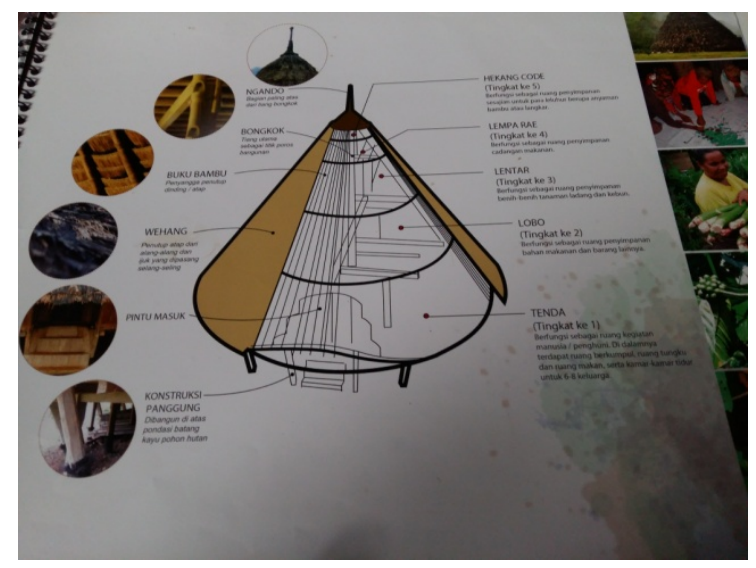

Gambar 4.3 Susunan Mbaru Niang

Sumber: Dokumentasi Pribadi, 2016

Tidak saja menawarkan keunikan mbaru niang, Kampung Waerebo juga memiliki keanekaragam hayati sebagai salah satu daya tarik yang dapat dinikmati oleh wisatawan. Daerah pegunungan yang berada pada ketinggian diatas 1.000 meter memiliki iklim yang lebih basah sehingga hutan yang berada di barat daya Flores ini tetap hijau selama setahun. Hutan pegunungan tersebut meliputi kawasan hutan Waerebo. Berdasarkan survei keanekaragan hayati pada tahun 2013 ditemukan 42 jenis pohon yang menyusun ekosistem hutan ini. Diantaranya adalah pohonpohon natu (planchonella firma), ketang (planchonella obovata), maras (dysoxylum $s p$ ), dan worok (Dysoxylum nutans) yang berada pada ruas ketinggian antara $761 \mathrm{mdpl}$ (Wae Lomba) sampai 1.099 mdpl (Poco Roko). Sedangkan di atas ketinggian $1.000 \mathrm{mdpl}$ dapat dijumpai pohon-pohon moak (dacrycarpus imbricatus). Pinus (podocarpus amarus), dan rukus (adinandra javanica) bersama jenis-jenis pohon khas pegunungan lainnya seperti kenti (leptosperum flavescens), rentigi (vaccinium timorensis), dan mpuing (decaspermum fruticosum). (Dokumentasi dari buku "PesanPesan dari Wae Rebo").
Keunikan mbaru niang dan keanekaragaman hayati menjadikan Waerebo sebagai destinasi yang sangat diminati oleh wisatawan. Selain itu terdapat juga upacara penti yaitu upacara syukur masyarakat Manggarai kepada Sang Pencipta atas segala rejeki dan berkat yang telah diberikan selama setahun. Masyarakat Manggarai memaknai penti sebagai simbol hubungan yang harmonis yang dibangun antara manusia dengan Tuhan, manusia dengan sesamanya, serta manusia dengan alam lingkungannya. Upacara penti dilaksanakan sebagai perayaan pesta tahun baru adat masyarakat Manggarai untuk mensyukuri segala kebaikan dan keberhasilan selama setahun dan memohon berkat serta perlindungan untuk tahun yang selanjutnya. Penti biasanya dilaksanakan pada setiap bulan November setiap tahunnya yang oleh masyarakat lokal disebut sebagai bulan bako yang merupakan awal bulan berdasarkan perhitungan siklus masyarakat Waerebo.

Tarian caci juga merupakan atraksi wisata yang banyak diminati oleh wisatawan terutama wisatawan mancanegara. Para pemeran tarian caci membutuhkan fisik yang kuat karena akan menampilkan adu ketangkasan dan kekuatan antara pemainnya yang saling mencambuk maupun menangkis cambukan lawan. Tarian caci yang hanya bisa diperankan oleh kaum laki-laki ini diidentikan dengan sifat keperkasaan laki-laki Manggarai karena menampilkan sikap keberanian, kejantanan, dan menjadi daya tarik bagi kaum perempuan.

\subsection{Kesesuaian Praktik Ekowisata dengan Konsep ekowisata menurut Fennel dan World Conservation Union (WCU) )}

Keberadaan Waerebo yang berada di tengah-tengah pegunungan dan jauh dari keramaian serta kampung-kampung tertangga, secara tidak langsung menjadikannya sebagai sebuah destinasi wisata berbasis ekowisata. Sesuai dengan pengertian ekowisata menurut Fennel (dalam Arida, 2009) yang menyatakan bahwa kegiatan ekowisata haruslah berbasis pada keaslian alam lingkungannya maka Kampung Waerebo sangat cocok untuk dikembangkan sebagai DTW berbasis ekowisata. Wisatawan yang ingin mengunjungi Kampung Waerebo harus melakukan perjalanan selama empat jam melewati jalanjalan kecil di dalam hutan dan melewati 
pegunungan. Dalam perjalanan wisatawan akan disuguhkan dengan keanekaragaman flora maupun fauna yang berada di sepanjang hutan menuju Kampung Waerebo.

Selain berbasis alam, suatu destinasi wisata dapat dikategorikan sebagai ekowisata apabila sudah memiliki sistem pengelolaannya sendiri. Masyarakat lokal yang ternaung dibawah Lembaga Pelestarian Budaya Waerebo (LPBW) bertanggung jawab terhadap segala kegiatan pariwisata yang terjadi di Kampung Waerebo. Lembaga pegelola ini memiliki struktur kepengurusan serta program-program yang jelas sehingga ekowisata dapat berjalan dengan baik sampai dengan saat ini. Beberapa bagian atau kelompok masyarakat yang berada dibawah tanggung jawab LPBW adalah kelompok pemandu lokal atau guide, kelompok porter, kelompok ibu-ibu yang menjual souvenir dan bertanggung jawab terhadap kebutuhan makan dan minum wisatawan.

Kampung Waerebo tidak akan menjadi seperti sekarang ini jika bukan karena bantuan dan pendampingan dari sebuah Lembaga Swadaya Masyarakat (LSM) yang bernama Indecon. Indecon merupakan sebuah LSM yang khusus bergerak dibidang ekowisata. Sejak masuknya Indecon ke Kampung Waerebo pada tahun 2006, Indecon telah banyak melakukan pendekatan maupun pendampingan kepada masyarakat lokal. Salah satu bentuk dukungan dari Indecon yang sangat dirasakan oleh masyarakat lokal adalah revitalisasi rumah adat atau mbaru niang. Sebelum direvitalisasi, hanya tersisa empat mbaru niang dan hanya tiga mbaru niang yang layak dihuni. Oleh karena itu pada tahun 2008 bersama dengan kelompok arsitek dari Jakarta, Indecon bersama-sama dengan masyarakat lokal membangun kembali ketujuh mbaru niang tersebut dengan tidak menghilangkan nilai keasliannya. Sampai dengan tahun 2016, Indecon telah mendampingi masyarakat lokal selama sepuluh tahun.

Selama sepuluh tahun masa pendampingan di Kampung Waerebo sejak tahun 2006 hingga tahun 2016, Indecon telah banyak membagikan pengetahuan maupun keterampilan kepada masyarakat lokal diantaranya adalah diberikan latihan memandu, pelatihan bahasa asing, dan pelatihan memasak bagi kaum ibu-ibu sehingga masyarakat lokal mampu memberikan pelayanan yang prima kepada wisatawan.

Selain kegiatan wisata yang berbasis alam, ekowisata juga harus mengedepankan upaya-upaya konservasi sehingga tetap menjaga kelestarian lingkungan dan mengutamakan partisipasi aktif dari masyarakat lokal dengan membeli atau menggunakan produk-produk lokal. Untuk tetap menjaga kelestarian lingkungan dan sebagai wujud dari upaya konservasi maka terdapat aturan-aturan yang mengikat wisatawan dan harus ditaati. Aturan-aturan tersebut seperti wisatawan dilarang merusak lingkungan dengan tidak memetik atau bahkan mencubit tumbuhan yang berada di kawasan hutan Kampung waerebo. Tidak hanya itu, wisatawan dilarang keras untuk berteriak atau mengeluarkan suara bising agar tidak menganggu hewan-hewan yang berhabitat di hutan. Sebagai wujud menghargai alam, limbah sisa makanan bagi wisatawan didaur ulang oleh masyarakat lokal yang digunakan sebagai makanan ternak. Sangat jarang ditemukan sampah-sampah plastik di Kampung Waerebo karena selain terdapat larangan keras untuk tidak membuang sampah di sembarangan tempat, untuk memenuhi kebutuhan makan dan minum wisatawan menggunakan hasil perkebunan masyarakat lokal seperti padi, sayur-mayur, dan buah-buahan.

Sedangkan konsep ekowisata menurut World Conservation Union (WCU dalam Arida,2009) yang menyatakan bahwa kegiatan ekowisata merupakan perjalanan yang mengunjungi daerah yang masih asli, menghargai keindahan alam, dan mengedepankan konservasi sudah dijalankan di Kampung Waerebo. Wisatawan yang akan mengunjungi Kampung Waerebo melakukan perjalanan selama kurang lebih empat jam dengan melewati hutan dan pegunungan dan diwajibkan membawa seorang pemandu lokal. Selama perjalanan, wisatawan akan dijelaskan mengenai keanekaragaman hayati yang terdapat di sepanjang hutan menuju Waerebo seperti berbagai jenis flora dan fauna. Tujuannya adalah wisatawan mendapatkan pengetahuan baru tentang keanekaragaman tumbuhan dan hewan tersebut sehingga muncullah sikap untuk menghargai alam. Dalam perjalanan menuju Kampung Waerebo, pemandu lokal mengharuskan wisatawan 
untuk menjaga kebersihan dan ketenangan dengan membawa kembali plastik-plastik sampah keluar dari kawasan Waerebo, dilarang merusak tumbuhan dengan mencubit atau memetik dedaunan maupun bunga serta dilarang mengeluarkan atau menghasilkan suara keras dengan tujuan tidak menganggu hewan yang berhabitat di dalam hutan.

Setibanya di Kampung yang otentik ini, wisatawan dapat menyaksikan keunikan dan kemegahan ketujuh mbaru niang yang mengitari sebuah altar yang disebut compang. Keberadaan mbaru niang semakin diperindah dengan pegunungan yang mengitari kampung ini. Sebelum memulai aktivitas di Kampung Waerebo, wisatawan harus memasuki rumah adat utama terlebih dahulu dan melaksanakan ritual adat serta diwajibkan menyumbangkan sejumlah uang kepada pengurus adat sebagai bentuk dan tanda penghormatan kepada leluhur sehingga wisatawan dapat diterima secara adat di Kampung Waerebo. Sejumlah uang yang diberikan tersebut digunakan untuk kegiatan konservasi.

Berdasarkan penjabaran diatas maka konsep ekowisata menurut Fennel dan World Conservation Union yang dapat disimpulkan sebagai sebuah perjalanan wisata yang mengunjungi suatu daya tarik yang masih asli baik alam maupun budayanya, mengutamakan kegiatan konservasi dan berorientasi pada kesejahteraan masyarakat lokal sebagian besar sudah sesuai dan dijalankan di Kampung Waerebo. Namun beberapa hal yang harus dibenahi adalah masih sangat minimnya fasilitas penginapan untuk wisatawan di Kampung Waerebo.

\section{SIMPULAN DAN SARAN}

\subsection{Simpulan}

Kampung Waerebo sudah menjalankan prinsip-prinsip pengembangan suatu daya tarik berbasis ekowisata yaitu kegiatan yang berbasis alam, mengutamakan upaya-upaya konservasi, dan mengedepankan kesejahteraan masyarakat lokal. Namun, dengan kehadiran Indecon sebagai pendamping masyarakat mengalami ketergantungan sehingga tidak memikirkan exit strategy yang nantinya mampu membuat masyarakat menjadi mandiri.

\subsection{Saran}

Berdasarkan pemaparan di atas, maka dapat diberikan beberapa saran sebagai berikut:

1. Lembaga Pelestarian Budaya Waerebo (LPBW) sebagai pengelola agar menjalin komunikai yang lebih intensif dengan masyarakat lokal baik yang bernanung dibawah lembaga maupun tidak sehingga dapat mencari jalan keluar untuk dapat menjalankan ekowisata secara mandiri tanpa kehadiran Indecon sebagai pendamping.

2. Dinas Pariwisata Kabupaten Manggarai agar memfasilitasi masyarakat lokal dengan program-program yang nyata untuk tetap menjaga kelestarian Waerebo sebagai sebuah DTW unggulan di kabupaten Manggarai

Daftar Pustaka:

Arida, I Nyoman Sukma. 2009. Meretas Jalan Ekowisata Bali. Denpasar. Udayana University Press.

Arikunto, S. 2010. Prosedur Penelitian Suatu Pendekatan Praktik Edisi Revisi. Jakarta: Rineka Cipta.

Damanik dan Weber F. 2006. Perencanaan Ekowisata dari Teori ke Aplikasi. Yogjakarta: Andi Offset.

Gunawan, Imam. 2013. Metode Penelitian Kualitatif Teori dan Praktik. Jakarta:Bumi Aksara.

Indecon, Infest. 2013. Pesan-pesan dari Waerebo. Jakarta.

Sugiyono. 2004. Metode Penelitian Bisnis. Bandung: Alfabeta. 